\title{
Size-at-Age in Haddock (Melanogrammus aeglefinus): Application of the Growing Degree-Day (GDD) Metric
}

\author{
Anna B. Neuheimer and Christopher T. Taggart \\ Dalhousie University, Department of Oceanography, \\ Halifax, Nova Scotia, Canada
}

\section{Kenneth T. Frank}

Department of Fisheries and Oceans, Bedford Institute of Oceanography, Ocean Sciences Division, Dartmouth, Nova Scotia, Canada

\begin{abstract}
While growth variation in fishes is the result of a number of different factors (temperature, food consumption, genetic composition, etc.), temperature has been identified as one controlling factor on fish sizeat-age. Thus, variation in size-at-age due to variation in temperature should be explained before the other factors are explored. We argue that the relevant metric for explaining temperature-dependent size-at-age variation in most fishes is physiologically relevant temperature; i.e., the thermal integral parameterized as the growing degree-day (GDD, ${ }^{\circ} \mathrm{C} \times \mathrm{d}$ ) metric. Accordingly, we employ GDD to examine the change in size-at-age (length-at-day, LaD) among eastern Scotian Shelf (Northwest Atlantic Fisheries Organization statistical divisions 4VW) haddock (Melanogrammus aeglefinus) from 1970 through 2003. Significant variation in length-at-day (LaD) among year classes (decline in slopes and intercepts of LaD-at-GDD relations) remains after $\mathrm{LaD}$ variation due to GDD (temperature) is explained. The unexplained variation is postulated to be a result of temperature-independent factors such as condition or size-selective fishing or both.
\end{abstract}




\section{Introduction}

Variation in fish size-at-age has a direct effect on vulnerability to fisheries, predator-prey interactions, and reproductive potential (Francis 1994). Thus, explaining or predicting growth variation through size-atage is essential to population and ecosystem studies as well as in determining fishing targets (e.g., size) and pressures suitable for sustainable fisheries. Variation in size-at-age may result from variation in a number of contributing factors-primarily temperature, food consumption, and genetic composition. Of these, temperature is a controlling factor governing metabolic reaction rates at the cellular level (Fry 1971) and affecting growth processes directly and indirectly (e.g., food consumption). Accordingly, time-dependent variations in temperature are reflected in time-dependent variations in development and in size-at-age where the latter is frequently used to infer growth rate. To properly examine the effect of variation in temperature on size-at-age among ectotherms one must use the correct time-scale (Gilbert et al. 1976). Instantaneous or average temperature estimates (e.g., daily or annual average) do not necessarily reflect the phenotypic expression of the time-based growth integral (size-at-age) in a complementary time-dependent manner; e.g., any point in a temperature time-series is instantaneous and thus aliased with respect to the size-at-age series. Instead, the growth integral is best examined using the time-based integral of the heat available for growth. For up to 270 years in some areas of ectotherm research (e.g., agriculture and entomology; Seamster 1950, Atkinson 1994, Bonhomme 2000) and recently in fish research (Neuheimer and Taggart 2007), the approximation of the thermal integral employed to describe size-at-age is the growing degree-day $\left(\mathrm{GDD},{ }^{\circ} \mathrm{C} \times \mathrm{d}\right)$. The GDD metric is a simple measure of daily temperature above a given threshold temperature. Among fishes it has been shown to explain between 92 and 99\% of variation in size-at-age over a range of species among environments, temperature regimes, and laboratory and field studies represented by 41 data sets (Neuheimer and Taggart 2007). Moreover, the same authors show that among data sets the GDD metric explains most of the sizeat-age variation that results from variation in the thermal history the integral) of a given fish species. Thus, the GDD metric compares fish size-at-age variation on a physiologically relevant time-scale, thereby disentangling size-at-age variation due to physiologically relevant variation in temperature from that which may be attributable to other factors such as food availability and genetic composition. While other factors will influence size-at-age, temperature should be investigated foremost and before much effort is invested in the alternatives (Brander 1995).

In this paper, we employ the GDD metric to examine variation in length-at-age $(\mathrm{mm})$ of the eastern Scotian Shelf (Northwest Atlantic Fisheries Organization, NAFO statistical division 4VW) haddock 


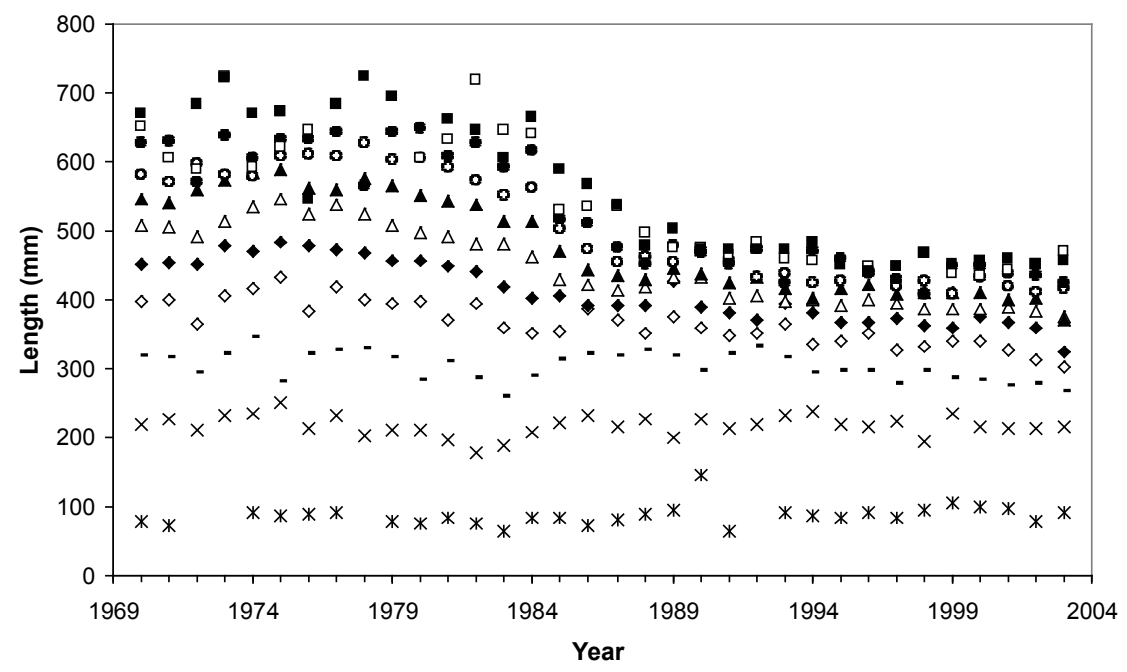

Figure 1. Variation in length $(\mathrm{mm})$ at age (year) for $4 \mathrm{VW}$ haddock from 1970 through 2003 (Frank et al. 2001) for ages 0+ (star), 1 (cross), 2 (horizontal line), 3 (open diamond), 4 (filled diamond), 5 (open triangle), 6 (filled triangle), 7 (open circle), 8 (filled circle), 9 (open square), and 10 (filled square).

(Melanogrammus aeglefinus) for the mature ages 5-10 over the period 1970-2003. This stock is considered to be a challenge for the utility of the GDD metric in explaining size-at-age variation given the profound reduction in size-at-ages $3+$ that has occurred over the past 30 years (Frank et al. 2001).

\section{Methods}

Haddock length-at-age (i.e., length-at-day, LaD, mm, Fig. 1) data for the NAFO division 4VW (Fig. 2) from 1970 through 2003 were obtained from the summer groundfish-trawl research vessel (RV) survey conducted annually by Fisheries and Oceans Canada. We restrict most analyses to mature haddock (ages 5-10; Mohn and Simon 2002) to avoid the allometry and discontinuities in LaD as a function of GDD that occur when life-history transformations such as maturation are marked by a change in energy allocation from growth to other physiological demands.

Monthly mean temperature data were extracted from the Bedford Institute of Oceanography hydrographic database for 1960-2006 and the $75 \pm 25 \mathrm{~m}$ depth stratum over the area on the Scotian Shelf that encompasses the majority of trawl locations and depths in the summer RV 


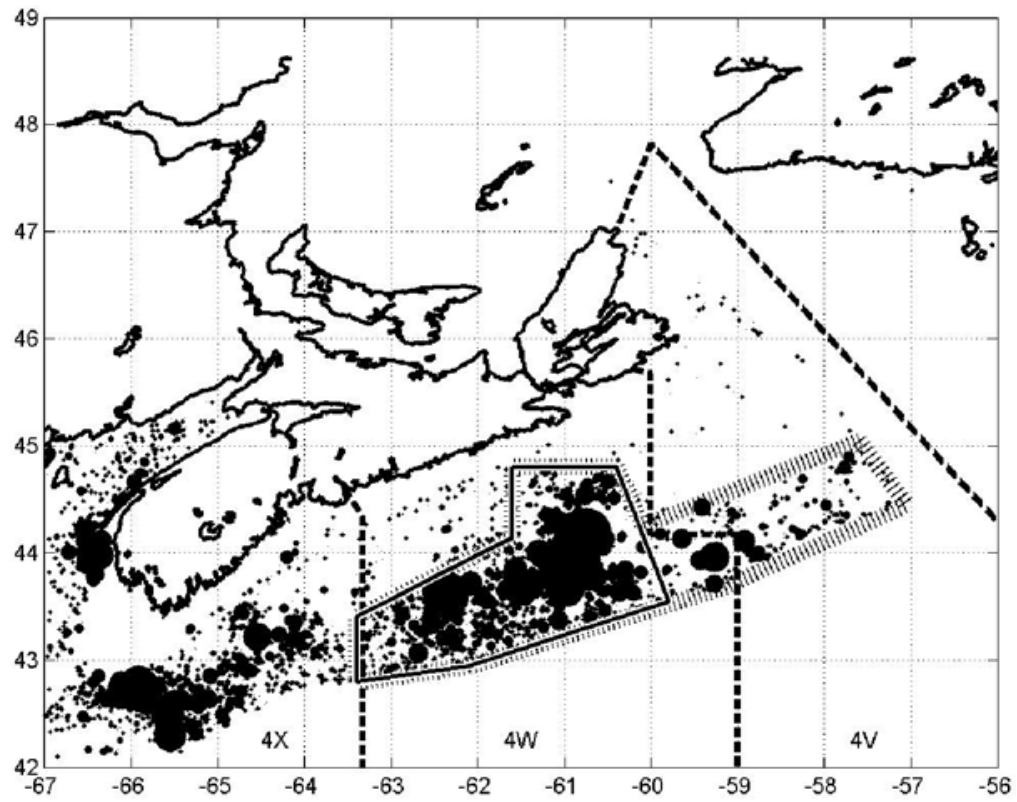

Figure 2. Chart showing the Northwest Atlantic Fisheries Organization (NAFO) statistical divisions $4 \mathrm{~V}, 4 \mathrm{~W}$, and $4 \mathrm{X}$ (dashed lines) on the Scotian Shelf off Nova Scotia, Canada, with locations of research vessel survey sampling stations associated with highest catch per unit effort of haddock (i.e., upper 3 quartiles of log-transformed effort-adjusted abundance, expanding filled circles) and polygons outlining the area wherein temperature was extracted from the Bedford Institute of Oceanography hydrographic database (polygon 1, hatched line, preliminary evaluation including divisions 4V and 4W; polygon 2, solid black line, subsequent evaluation including only division $4 \mathrm{~W}$; see Discussion).

survey area associated with the highest haddock catch per unit effort; i.e., upper 3 quartiles of log-transformed effort-adjusted abundance (Fig. 2 , polygon 1). The mean monthly temperature estimates were linearly interpolated (month to month) where necessary (Fig. 3). The interpolated temperature series was then smoothed using a uniformly weighted, centered 25-month moving average to provide the daily estimates. Analysis performed with 13-month, 37-month, and 61-month moving averages (to examine the influence of moving average extent) led to similar results in all cases. The GDD at day $n\left({ }^{\circ} \mathrm{C} \times \mathrm{d}\right)$ is calculated as 


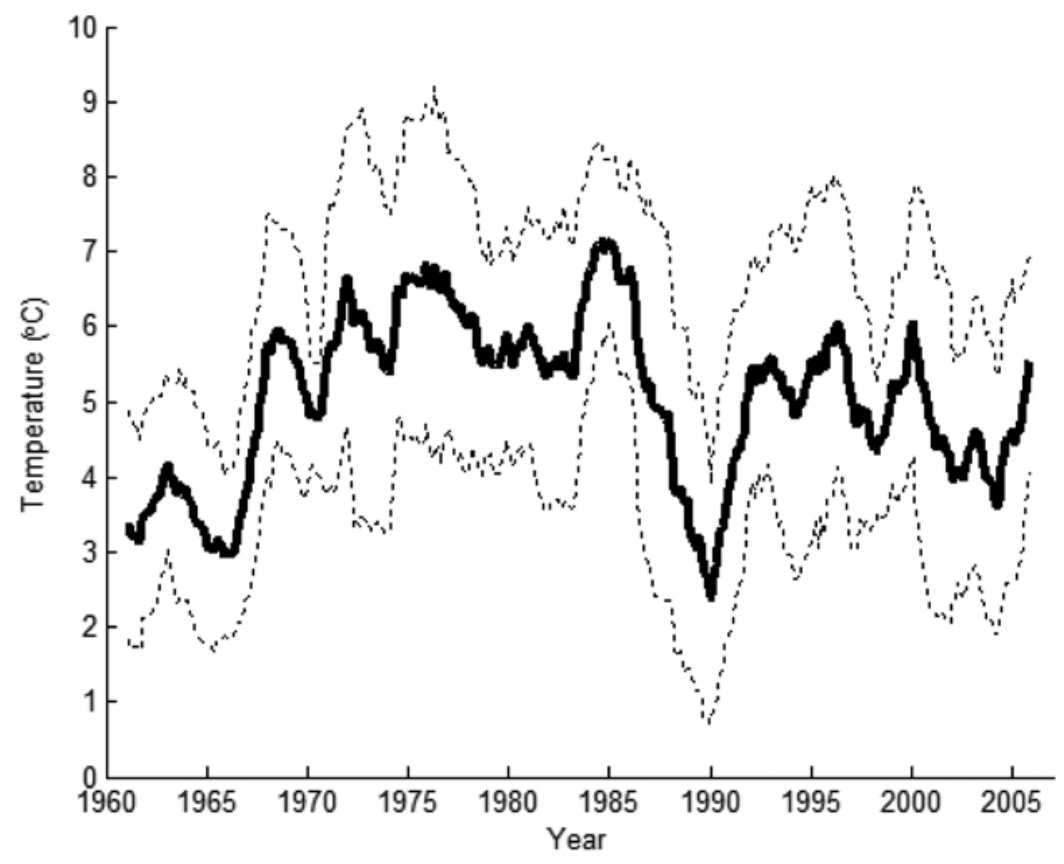

Figure 3. Smoothed (25-month centered moving average) interpolated monthly average temperature $\left({ }^{\circ} \mathrm{C}\right.$, solid line) \pm one standard deviation ( ${ }^{\circ} \mathrm{C}$, dotted lines) for polygon 1 in Fig. 2 . Data from the Bedford Institute of Oceanography hydrographic database.

$$
G D D(n)=\sum_{i=1}^{n}\left(T_{i}-T_{T h}\right) \times \Delta d, \quad T_{i} \geq T_{T h}
$$

where $T_{i}$ is the temperature estimate at day $i, T_{T h}$ is the predetermined threshold temperature $\left(T_{T h}=0^{\circ} \mathrm{C}\right.$, see Neuheimer and Taggart 2007) and $\Delta d$ is the time step (sampling frequency, i.e., $1 \mathrm{~d}$ ). Variation in LaD and GDD for each year class was compared and quantified through linear regression according to

$$
L a D=\beta \times G D D+\alpha
$$

where $\beta$ is the slope, $m m \times\left({ }^{\circ} \mathrm{C} \times \mathrm{d}\right)^{-1}$, and $\alpha$ is the intercept, $\mathrm{mm}$, of the LaD-at-GDD relation. Neuheimer and Taggart (2007) demonstrated that in most cases LaD-at-GDD exhibits a strong linear relation. 
Table 1. Parameters for age-dependent linear regression of length-at-age ( $\mathrm{mm})$ on year (1970-2003) for NAFO division 4VW haddock.

\begin{tabular}{cccccc}
\hline Age & $\begin{array}{c}\text { Slope } \\
(\mathrm{mm} \text { per year })\end{array}$ & $\begin{array}{c}\text { Intercept } \\
(\mathrm{mm}) \times 10^{3}\end{array}$ & $r^{2}$ & $P$-value & $\begin{array}{c}\text { Sample } \\
\text { size }(\mathrm{n})\end{array}$ \\
\hline 0 & & & & 0.09 & 30 \\
1 & & & & 0.80 & 34 \\
2 & -1.0 & 2.3 & 0.22 & 0.005 & 34 \\
3 & -2.8 & 5.9 & 0.76 & $<0.001$ & 34 \\
4 & -4.2 & 8.7 & 0.87 & $<0.001$ & 34 \\
5 & -5.3 & 11.0 & 0.87 & $<0.001$ & 34 \\
6 & -6.7 & 13.7 & 0.87 & $<0.001$ & 34 \\
7 & -7.2 & 14.9 & 0.84 & $<0.001$ & 34 \\
8 & -7.8 & 16.0 & 0.80 & $<0.001$ & 34 \\
9 & -7.7 & 15.8 & 0.73 & $<0.001$ & 31 \\
10 & -9.3 & 19.1 & 0.81 & $<0.001$ & 32 \\
\hline
\end{tabular}

\section{Results}

NAFO-4VW haddock show a significant decline in length-at-age for ages $3+$ from the mid-1970s through to the early 1990s with the highest rate of decline occurring over the 1982-1989 period (Fig. 1, Table 1). Length-at-age for ages $0+$ and -1 show no trend over time and for age 2 the relation is marginal as time (year) explains $22 \%$ of the length-at-age variation relative to $>73 \%$ for ages- $3+$ and older (Table 1 ).

Bathypelagic $(75 \pm 25 \mathrm{~m})$ water temperature within the domain of high haddock abundance on the eastern Scotian Shelf exhibited rapid cooling during the mid to late 1980s followed by rapid warming in the early 1990s (Fig. 3). Contrary to expectations, variation in GDD within the stock, at shelf scales, did not explain the majority of variation in length-at-day among haddock year classes as it does, for example, among 17 cod stocks at ocean basin scales (Neuheimer and Taggart 2007). There is nearly as much variation in LaD as a function of physiological time (GDD) across year classes as there is $\mathrm{LaD}$ as a function of calendar time (Fig. 4). There was significant variation among LaD-at-GDD relations for the 1965-1996 year classes (Fig. 4b, ANCOVA, different slopes $P<0.0001$ ). By inspection (Fig. 4), the year classes were aggregated into two periods, prior to 1979 and 1979 and later, to compare the LaD-at-GDD relations (i.e., slope and intercept; Fig. 5). The LaD as a function of GDD relations among the $<1979$ year classes demonstrate similar slopes $(P=0.43)$ and differing intercepts $(P=0.0018)$ and there is no time-dependent trend in the intercepts (Fig. 5b, linear regression, $P=0.71$ ). The LaD as a function of GDD relations among the $\geq 1979$ year 

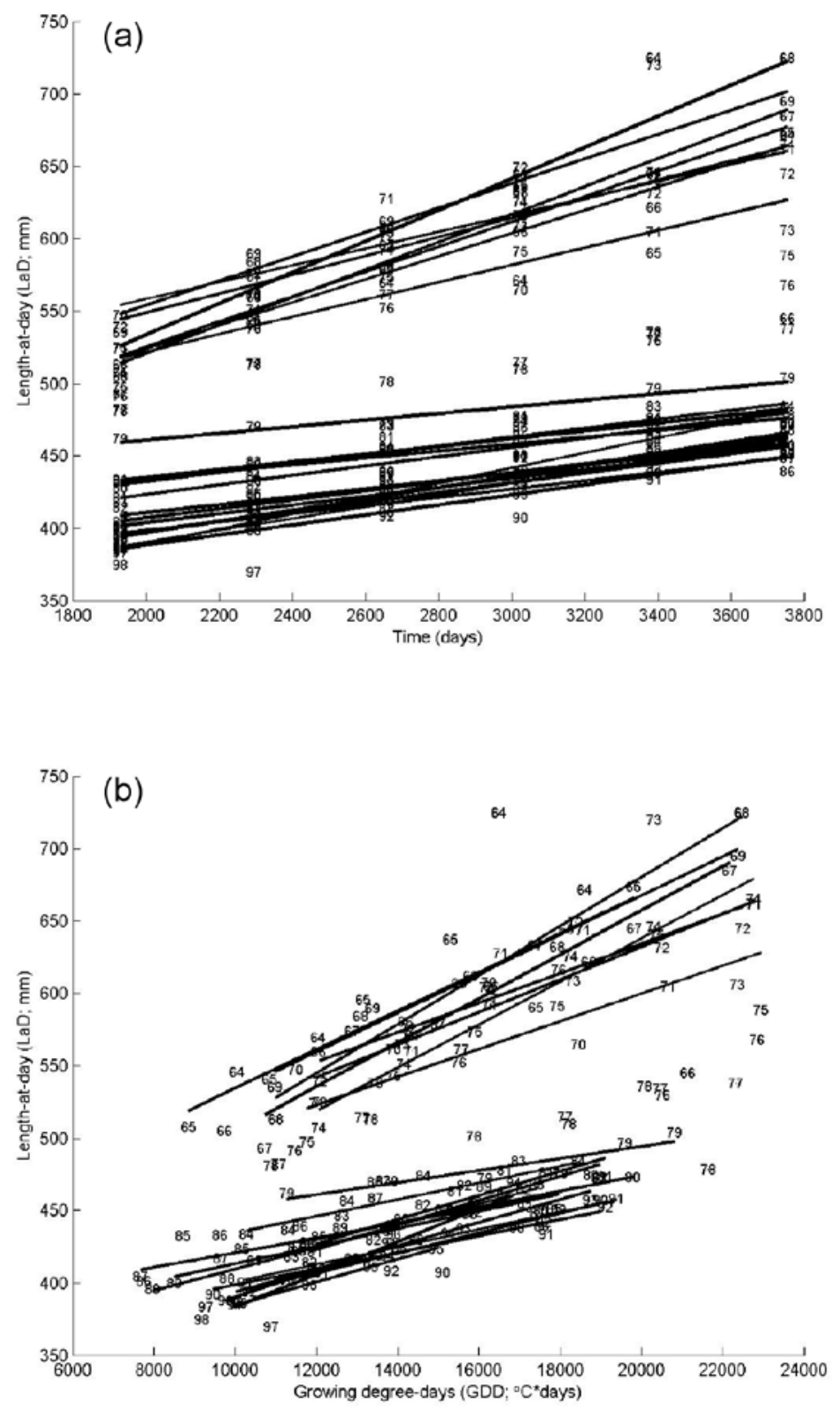

Figure 4. Length-at-day $(\mathrm{mm})$ for $4 \mathrm{VW}$ haddock ages 5-10 as a function of (a) calendar time (days, significant variation among year class relations, ANCOVA, different slopes $P<0.0001$ ); and as a function of (b) GDD ( ${ }^{\circ} \mathrm{C} \times \mathrm{d}$, significant variation among year class relations, ANCOVA, different slopes $P<\mathbf{0 . 0 0 0 1}$ ). Data-labels denote yearclass decade and year in the 1900s. 

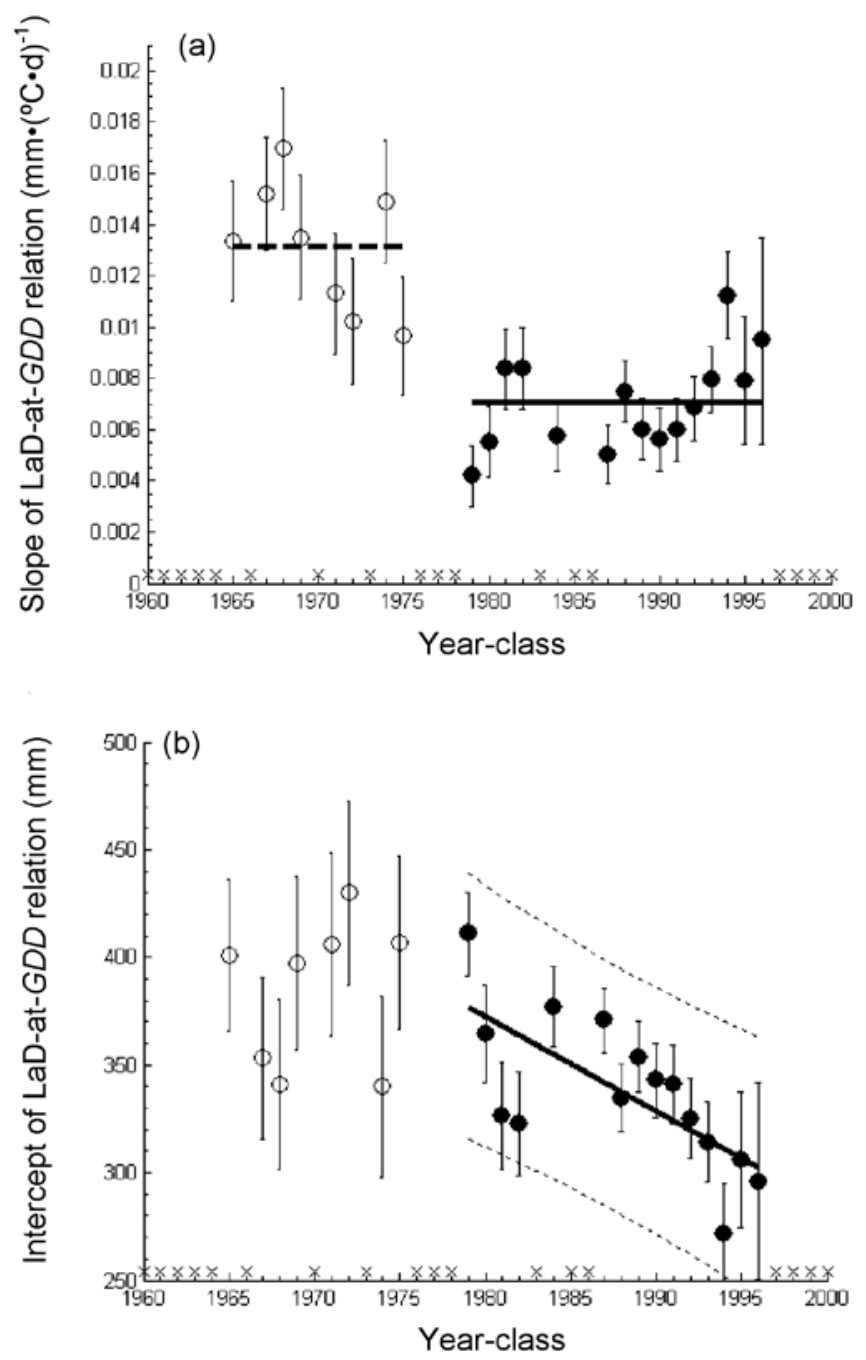

Figure 5. Parameters of the LaD-at-GDD relation for early $(<1979$, open circles) and late ( $\geq 1979$, filled circles) year classes. (a) Slopes, $\mathrm{mm} \times\left({ }^{\circ} \mathrm{C} \times \mathrm{d}\right)^{-1}$, and associated standard error of the LaD-at-GDD relations are similar within early (open circles, dashed horizontal line) and late (filled circles, solid horizontal line) year classes. (b) Intercepts, $\mathrm{mm}$, and associated standard error of the LaD-atGDD relations are different within early (open circles) and late (filled circles) year classes. There was a significant decline in the intercept among late year classes (solid line, linear regression dashed lines indicate $95 \%$ confidence intervals around the prediction). Crosses denote year classes with non-significant $(P>0.05)$ LaD-at-GDD relations. 
classes also demonstrate similar slopes $(P=0.17)$ but unlike the earlier year classes there is a near-systematic year-class-dependent decay in the intercepts of the LaD-at-GDD relations (Fig. 5b. linear regression, $r^{2}$ $=0.50, P=0.003)$. Further, the mean slope of the LaD-at-GDD relation for the $<1979$ year classes is $0.013 \pm 0.0009 \mathrm{~mm} \times\left({ }^{\circ} \mathrm{C} \times \mathrm{d}\right)^{-1}$ and is nearly twice that (Fig. 5a, Shapiro-Wilk normality test: $P>0.62$; two-sample $t$-test: $P<0.0001)$ estimated for the $\geq 1979$ year classes at $0.007 \pm 0.0004$ $\mathrm{mm} \times\left({ }^{\circ} \mathrm{C} \times \mathrm{d}\right)^{-1}$.

\section{Discussion}

The NAFO-4VW haddock stock experienced a decline in LaD in the 1980s that was coincident with changes in a number of factors affecting fish growth, as inferred through population size-at-age; factors that included a doubling of the fishing effort and a decrease in water temperature (Zwanenburg 2000). As a first step toward disentangling the various factors that could potentially explain the variation in haddock lengthat-age, we turned to temperature as Brander (1995) suggests we must, and examined variation in $\mathrm{LaD}(\mathrm{mm})$ with $\mathrm{GDD}\left({ }^{\circ} \mathrm{C} \times \mathrm{d}\right)$ as a function of variation in year-class thermal history; i.e., the physiologically relevant measure of temperature. In doing so we find the thermal integral explains only a small portion of the variation in LaD among the 4VW haddock year classes.

A major requirement for employing the GDD metric is that the temperature measure used is representative of that experienced by the organism over the growth period of interest (Neuheimer and Taggart 2007). Over the period we examine here, the distribution of the $4 \mathrm{VW}$ haddock generally shifted from an area restricted primarily to division $4 \mathrm{~W}$ (polygon 2, Fig. 2) for the 1965-1974 year classes to an area generally including divisions $4 \mathrm{~V}$ and $4 \mathrm{~W}$ (polygon 1, Fig. 2) for the 1975-1984 year classes, and then back to division 4W for the 1985-1994 year classes. Bathypelagic water temperatures for polygons 1 and 2 demonstrate similar cooling in the mid to late 1980s and warming in the early 1990s, and though the uncertainties (standard deviations) are large in either case (Fig. 6a), the temperature in polygon 2 was warmer than that in polygon 1 (Fig. 6b) for most of the time. During both the early $(<1979)$ and late $(\geq 1979)$ periods of year-class groupings, the majority of the stock was restricted to division $4 \mathrm{~W}$ (polygon 2, Fig. 2). Consequently, we ask, if we limit our temperature analyses to the polygon 2 temperature estimates, do we find that GDD is better able to explain the variation in LaD among the early and late groupings of year classes? The answer was unequivocally no, as we resolved similar relations among year classes as were resolved using the polygon 1 temperature data. The only difference was a slightly lower slope in the mean LaD-at-GDD relation for the late year classes using the polygon 2 temperature data, $0.006 \pm$ 

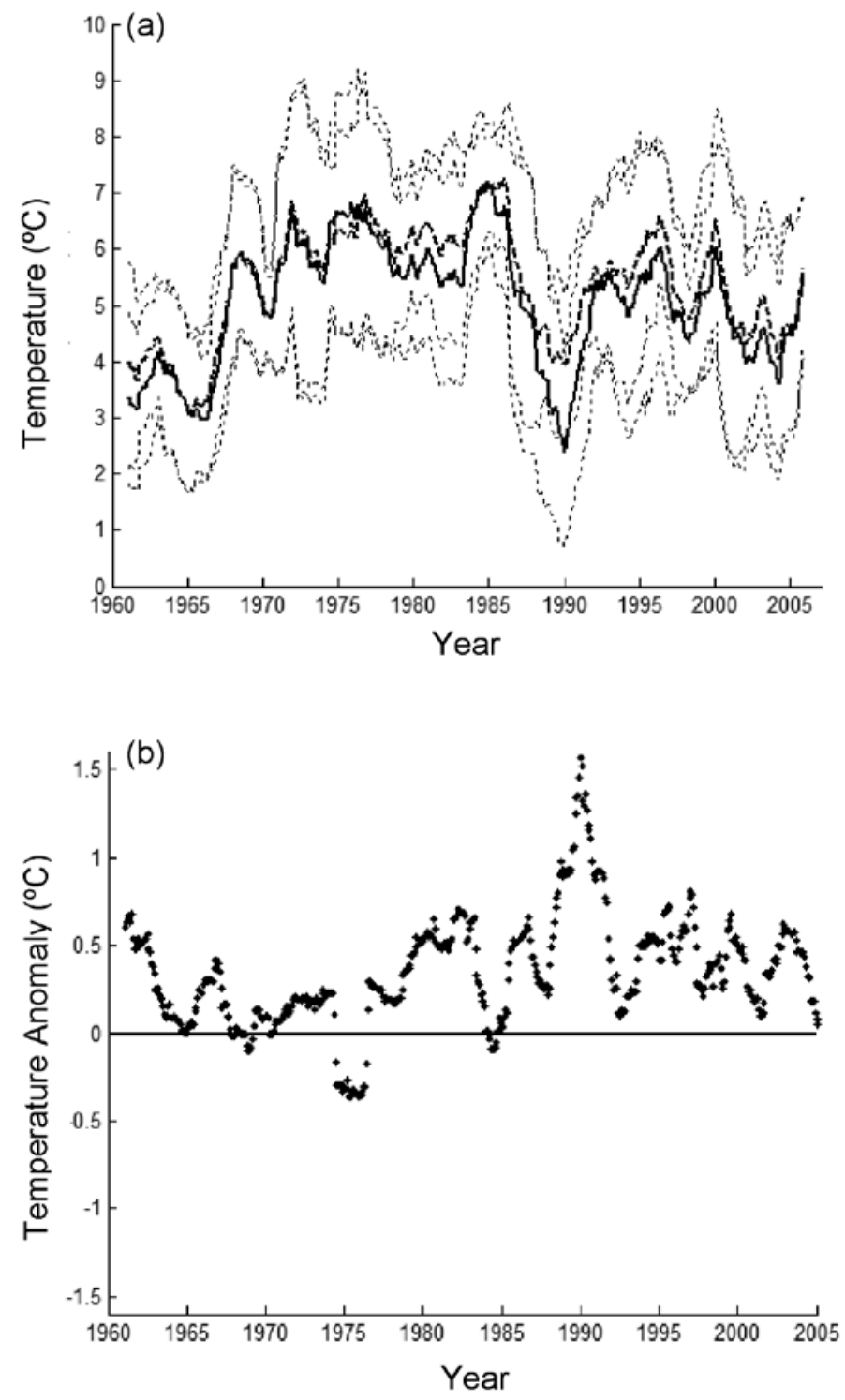

Figure 6. (a) Smoothed (25-month centered moving average) interpolated monthly average temperature $\left({ }^{\circ} \mathrm{C}\right) \pm$ one standard deviation $\left({ }^{\circ} \mathrm{C}\right.$, dotted lines) for polygon 1 (solid line) and polygon 2 (dashed line) illustrated in Fig. 2 and (b) temperature anomaly calculated using the polygon 1 and polygon 2 smoothed temperature series. Data from the Bedford Institute of Oceanography hydrographic database. 


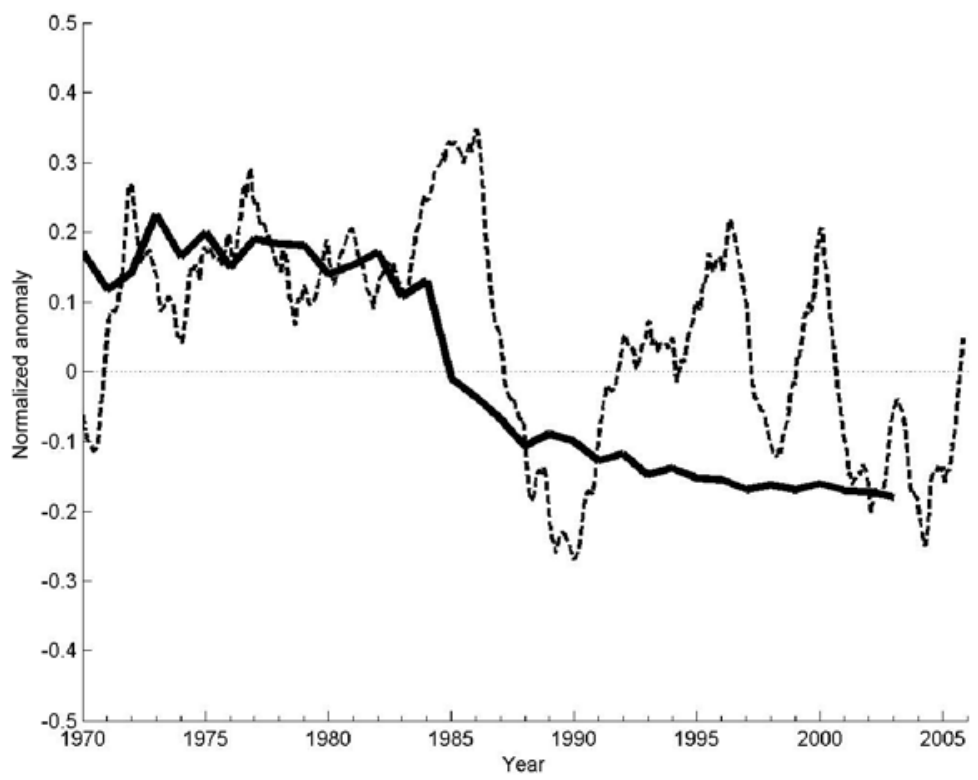

Figure 7. Normalized anomalies of mean length for ages 5-10 (solid line) and smoothed (25-month moving average) interpolated monthly mean temperature (dashed line, from polygon 1, see Fig. 3 ).

$0.0004 \mathrm{~mm} \times\left({ }^{\circ} \mathrm{C} \times \mathrm{d}\right)^{-1}$, relative to that of polygon $1,0.007 \pm 0.0004 \mathrm{~mm}$ $\times\left({ }^{\circ} \mathrm{C} \times \mathrm{d}\right)^{-1}$; each nearly half that exhibited for the earlier year classes (see above). Therefore, when distributional changes and the associated temperatures are incorporated into the analyses the majority of variation in LaD among year classes remains unexplained.

In summary, the above analyses show that variation in thermal history (GDD) is unable to explain the majority of variation in LaD among 4VW haddock year classes on the Scotian Shelf despite the fact that cooler water is often cited as a primary source of the size-at-age decline in this stock (e.g., Trippel 1995). The cold water argument is most easily attributed to observations of the decline in temperature on the shelf appearing to occur concurrently with the decline in LaD for this stock. However, the decline in size-at-age precedes that of temperature by approximately 3 years as illustrated by calculating the normalized anomalies for mean length-at-ages 5-10 and temperature (Fig. 7). Furthermore, when temperatures returned to near-normal in the 1990s, the size-at-age did not return to near-normal but continued to decline (see also Zwanenburg 2000, Drinkwater and Frank 2001). These conclusions remain when we employ time to examine LaD and when we use the 
integrated temperature measure (GDD); the preferred metric particularly when various year classes with different growth (and thermal) histories are involved and when spatially different thermal histories related to distributional changes in the stock are considered. Further, perhaps the most compelling argument is based on the evidence that LaD for $4 \mathrm{VW}$ haddock ages 0,1 , and marginally so for 2 , remain unchanged regardless of the thermal environment (integrated or not). Age-0 haddock occupy pelagic waters for approximately four months before becoming bathypelagic along with older age-classes (DFO 2001). If temperature was the major source of variation in LaD, one would expect the youngest ages to be equally affected (Drinkwater and Frank 2001) and this is not the case (Fig. 1, Table 1).

It is clear that temperature variation, as parameterized through the thermal integral, does not explain the decline in $4 \mathrm{VW}$ haddock size-atage over the study period. However, it has been shown elsewhere that temperature can explain LaD among fish, within species, in many environments if the comparisons are made using the same physiological timescale (i.e., GDD), and where it does not, it is an indication that the residual variation in $\mathrm{LaD}$ can be attributed to other factors (Neuheimer and Taggart 2007). Here we employed the GDD metric to identify the portion of variation in size-at-age that is attributable to variation in thermal history. The question becomes: what other factors may explain the remaining size-at-age variation in the $4 \mathrm{VW}$ haddock; i.e., the variation in slopes and intercepts of LaD-at-GDD relations among year classes shown in Fig. 5? We postulate that the unexplained variation may be attributable to changes in fishing pressure (e.g., Olsen et al. 2004). Most fishing gear is size-selective (Sinclair et al. 2002). If a portion of the phenotypic variation in size-at-age is rooted in genetic variation, it is possible that fishing mortality (often exceeding natural mortality by a factor of 2 or 3) may represent a strong genetic selection on a population (Engelhard and Heino 2004, Hutchings 2005) resulting in evolutionary changes in growth and maturation (Law 2000, Stokes and Law 2000). Evidence for these impacts of size-selective fishing is noted elsewhere in the North Atlantic; greater reductions in size-at-age are found in target than non-target species (Zwanenburg 2000).

Management strategies differ depending on the sources of the variation in size-at-age, requiring the causal mechanisms to be identified before management can be successful (Sinclair et al. 2002). Indeed, "failure to simultaneously consider alternative mechanisms, especially size-selective mortality, can lead to incorrect conclusions about the role of environmental factors in determining growth of fishes" (Sinclair et al. 2002). Thus the ability to assess the effects of fishing pressure on the variation in size-at-age of a population lies in the ability to disentangle those effects from other possible sources of size-at-age variation (e.g., temperature, etc.). Here we have extricated the influence of temperature 
variation on $\mathrm{LaD}$ in $4 \mathrm{VW}$ haddock. The next phase of our work is focused on examining the influence of size-selective fishing on the systematic decline in size-at-age found in this stock.

\section{Acknowledgments}

We are grateful to K. Drinkwater for comments and suggestions and D. Gregory for help with the Bedford Institute of Oceanography database. A Natural Sciences and Engineering Research Council of Canada PGS-D Scholarship to ABN and Discovery Grant to CTT supported this research. The comments and suggestions of two anonymous referees contributed to improvements in this paper and we thank them.

\section{References}

Atkinson, D. 1994. Temperature and organism size: A biological law for ectotherms? Adv. Ecol. Res. 25:1-58.

Bonhomme, R. 2000. Bases and limits to using 'degree.day' units. Eur. J. Agron. 13:1-10.

Brander, K.M. 1995. The effect of temperature on growth of Atlantic cod (Gadus morhua L.). ICES J. Mar. Sci. 52:1-10.

DFO. 2001. Eastern Scotian Shelf haddock (Div. 4TVW). Fisheries and Oceans Canada Science Stock Status Report A3-06.

Drinkwater, K.F., and K.T. Frank. 2001. Temperature and density-dependent effects on the size-at-age of haddock (Melanogrammus aeglefinus) on the Scotian Shelf. ICES CM 2001/V:10.

Engelhard, G.H., and M. Heino. 2004. Maturity changes in Norwegian springspawning herring Clupea harengus: Compensatory or evolutionary responses? Mar. Ecol. Prog. Ser. 272:245-256.

Francis, M.P. 1994. Growth of juvenile snapper, Pagrus auratus. N. Z. J. Mar. Freshw. Res. 28:201-218.

Frank, K.T., R.K. Mohn, and J.E. Simon. 2001. Assessment of the status of div. 4TVW haddock: 2000. Canadian Science Advisory Secretariat Research Document 2001/100.

Fry, F.E.I. 1971. The effect of environmental factors on the physiology of fish. In: W.S. Hoar and D.J. Randall (eds.), Fish physiology, Vol. VI. Environmental relations and behavior. Academic Press, London, pp. 1-99.

Gilbert, N., A.P. Gutierrez, B.D. Frazer, and R.B. Jones. 1976. Ecological relationships. W.H. Freeman and Company, San Francisco. 157 pp.

Hutchings, J.A. 2005. Life history consequences of overexploitation to population recovery in Northwest Atlantic cod (Gadus morhua). Can. J. Fish. Aquat. Sci. 62:824-832.

Law, R. 2000. Fishing, selection, and phenotypic evolution. ICES J. Mar. Sci. 57:659-668. 
Mohn, R., and J. Simon, 2002. Biological information relevant to the management of 4TVW haddock, RAP October 2002. Canadian Science Advisory Secretariat Research Document 2002/102.

Neuheimer, A.B., and C.T. Taggart. 2007. Growing degree-day and fish size-atage: The overlooked metric. Can. J. Fish. Aquat. Sci. 64:375-385.

Olsen, E.M., M. Heino, G.R. Lilly, M.J. Morgan, J. Brattey, B. Ernande, and U. Dieckmann. 2004. Maturation trends indicative of rapid evolution preceded the collapse of northern cod. Nature 428:932-935.

Seamster, A.P. 1950. Developmental studies concerning the eggs of Ascaris lumbricoides var. suum. Am. Midl. Nat. 43:450-470.

Sinclair, A.F., D.P. Swain, and J.M. Hanson. 2002. Disentangling the effects of size-selective mortality, density, and temperature on length-at age. Can. J. Fish. Aquat. Sci. 59:372-382.

Stokes, K., and R. Law. 2000. Fishing as an evolutionary force. Mar. Ecol. Prog. Ser. 208:307-309.

Trippel, E.A. 1995. Age at maturity as a stress indicator in fisheries. Bioscience 45:759-771.

Zwanenburg, K.C.T. 2000. The effects of fishing on demersal fish communities of the Scotian Shelf. ICES J. Mar. Sci. 57:503-509. 